\title{
Slip distribution of the 2003 northern Miyagi earthquake (M6.4) deduced from geodetic inversion
}

\author{
Satoshi Miura, Yoko Suwa, Toshiya Sato, Kenji Tachibana, and Akira Hasegawa \\ Research Center for Prediction of Earthquakes and Volcanic Eruptions, \\ Graduate School of Science, Tohoku University, \\ Sendai 980-8578, Japan \\ (Received October 14, 2003; Revised January 29, 2004; Accepted February 9, 2004)
}

\begin{abstract}
On July 26, 2003, a disastrous earthquake with M6.4 struck the northern part of Miyagi prefecture, northern Honshu, Japan. GPS measurements and leveling surveys conducted by the Geographical Survey Institute (GSI) revealed clear evidence of coseismic deformation. We analyzed those data using a geodetic inversion to estimate the slip distribution on a curved fault plane, which is suggested by precise hypocenter determination performed by Tohoku University. The maximum slip area is located at the northern and shallower part of the fault plane, which is consistent with the slip distribution obtained by seismic waveform inversion. The spatial pattern of slip direction also shows good agreement with that of the focal mechanism.
\end{abstract}

Key words: GPS, leveling survey, 2003 northern Miyagi earthquake (M6.4), geodetic inversion, slip distribution.

\section{Introduction}

A shallow crustal earthquake with magnitude 6.4 occurred at 07:13 (local time, LT) on July 26, 2003 in the northern part of Miyagi prefecture, northeastern Japan (hereafter, we refer to it as the 2003 northern Miyagi earthquake), accompanied by remarkable foreshock and aftershock sequences with the largest events of magnitude 5.6 (00:13 LT) and 5.5 (16:56 LT), respectively. More than 600 people were injured and more than 10,000 houses were damaged by the earthquake, because its focus was located just beneath the residential district at a depth of about $7 \mathrm{~km}$. Okada et al. (2003) obtained a very clear aftershock distribution along a curved plane by applying the double-difference hypocenter determination technique (Waldhause and Ellsworth, 2000) to data obtained from a dense temporary seismic network established by Tohoku University about ten hours after the main shock and just above the focal region. They also investigated source mechanisms from the foreshock sequence to the aftershock sequence to reveal a systematic spatial variation: the direction of the $P$-axis rotates from NE-SW at the northern part to NW-SE at the southern part. Yagi et al. (2003) carried out a seismic waveform inversion and derived a coseismic slip distribution on the presumed fault planes for the main shock, the largest foreshock, and the largest aftershock. Their result indicates that the maximum slip occurred around the northern part of the aftershock area.

Large earthquakes with magnitudes of about 7.5 have repeatedly occurred on the plate boundary east of Miyagi prefecture (e.g. Seno et al., 1980). The most recent one took place in 1978, i.e., the M7.4 Miyagi-oki earthquake. It is located just east of the source area of the 2003 northern Miyagi

Copy right (c) The Society of Geomagnetism and Earth, Planetary and Space Sciences (SGEPSS); The Seismological Society of Japan; The Volcanological Society of Japan; The Geodetic Society of Japan; The Japanese Society for Planetary Sciences; TERRAPUB. earthquake. Based on the record of repeated occurrences of earthquakes with magnitudes of about 7.5, the Headquarters of Earthquake Research Promotion of Japan evaluated that the next Miyagi-oki earthquake will occur with a probability of about $40 \%$ in the next 10 years. In response to this seismic hazard assessment, the Geographical Survey Institute of Japan (GSI) carried out campaign-style GPS measurements and leveling surveys around the focal area of the 2003 northern Miyagi earthquake just before and just after its occurrence to reveal clear evidence of coseismic deformation (Nishimura et al., 2003). They proposed a dual-fault model to explain the observed displacements. The calculated displacements from the model agree well with the observed ones. However, it is unrealistic that the two fault planes partially overlap each other, because the precise hypocenter distribution (PHD) obtained by Okada et al. (2003) does not support such a fault-geometry. In this study we used their proposed curved fault surface to estimate the slip distribution on a more realistic fault plane by means of a geodetic inversion technique (Yabuki and Matsu'ura, 1992).

\section{Data}

The nationwide GPS network, GEONET, composed of more than 1000 stations has been established by GSI (Miyazaki et al., 1997). The network has provided many important observational results, such as the detection of co- and post-seismic deformation (e.g. Heki et al., 1997; Nishimura et al., 2000), volcanic deformation (e.g. Miura et al., 2000), and the discovery of strain concentration zones (e.g. Sagiya et al., 2000; Miura et al., 2002), facilitating the immense progress that has been made in our knowledge of on-going crustal deformation. Baseline lengths of the network, however, are about $25 \mathrm{~km}$ on average, which is not short enough to obtain a geodetic fault model for M6-class earthquakes such as in the case of this study. 


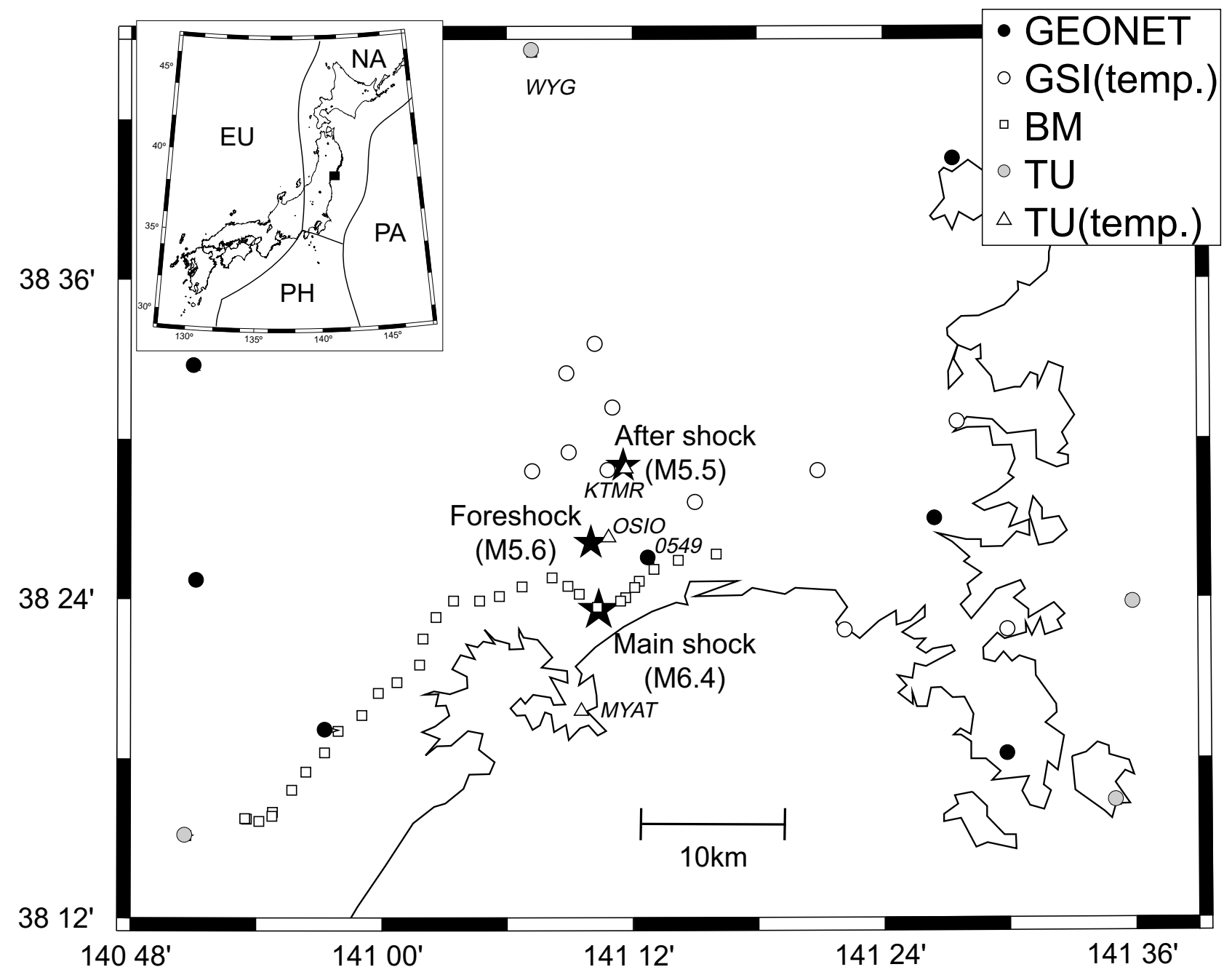

Fig. 1. Map showing geodetic stations in the study area. Black and gray circles denote continuous GPS stations operated by the Geographical Survey Institute of Japan (GSI) and Tohoku University (TU), respectively. Open circles and triangles indicate temporary GPS stations occupied before and after the earthquake by GSI, and continuous GPS stations installed after the earthquake. Open squares are benchmarks for the leveling survey conducted by GSI.

In addition to the continuous GPS stations, GSI had established some temporary stations to make up for the sparseness of the network in the source area of the 2003 northern Miyagi earthquake, because of the imminent Miyagi-oki earthquake as mentioned in the previous section. Right after the main shock, GSI reoccupied those temporary stations and also carried out a leveling survey to reveal any coseismic displacements. Figure 1 shows the locations of the geodetic stations around the source region of the M6.4 event. Horizontal and vertical coseismic displacements at these stations are shown in Figs. 2(a) and 2(b) by black arrows and black triangles, respectively. Errors in estimating the horizontal coseismic displacements derived at continuous GPS sites range from 2 to $3 \mathrm{~mm}$, while those at temporary stations may be two times greater or more because they were occupied two days or less before and after the earthquake. Time series of site coordinates obtained at Station 0549 of GEONET, the closest to the main shock, is shown in Fig. 2(c), as an example. Remarkable coseismic displacements due to the northern Miyagi earthquake amount to about $16 \mathrm{~cm}$ directed to the southeast, and about $8 \mathrm{~cm}$ of uplift. Minor coseismic displacements at the end of May, 2003, were caused by the
May 26 M7.1 earthquake, which occurred in the subducting slab at a depth of about $70 \mathrm{~km}$ with an epicentral distance of about $60 \mathrm{~km}$ to the northeast of the site.

Horizontal displacements direct eastward and westward in the far western and eastern areas, respectively, from the source area, while distinct upheaval was observed around the source area. This overall feature of coseismic deformation suggests a thrust-type source mechanism and agrees well with the moment tensor and focal mechanism obtained by Okada et al. (2003). In the next section, using the data from GSI stations together with coseismic displacements observed at continuous GPS sites operated by Tohoku University (Fig. 1), we estimate the slip distribution on the curved fault surface presumed from the PHD obtained by Okada $e t$ al. (2003).

\section{Slip Distribution Estimated by Geodetic Inver- sion}

Tohoku University deployed a dense temporary seismic network soon after the main shock just above the focal region (Umino et al., 2003). Okada et al. (2003) demonstrated a very sharp and clear aftershock distribution along a curved 


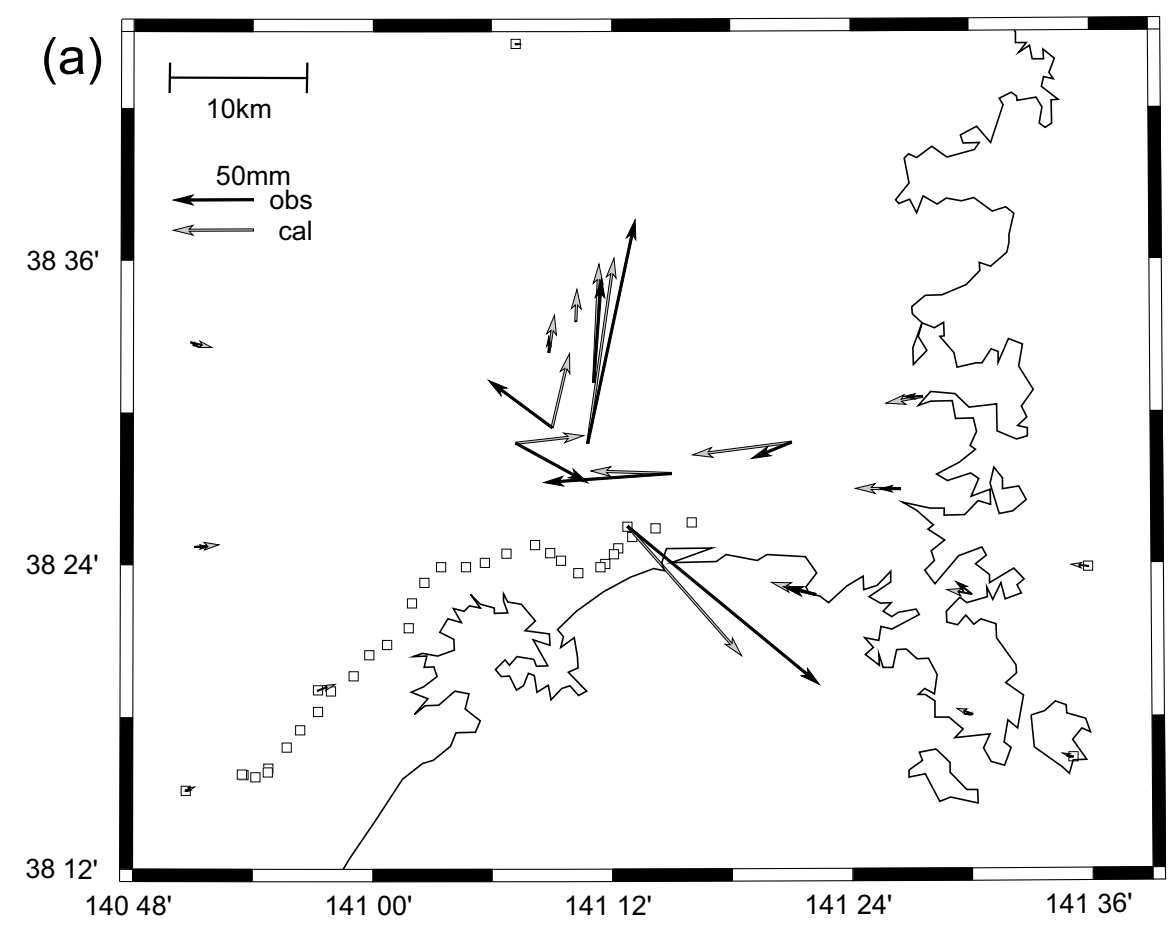

(b)
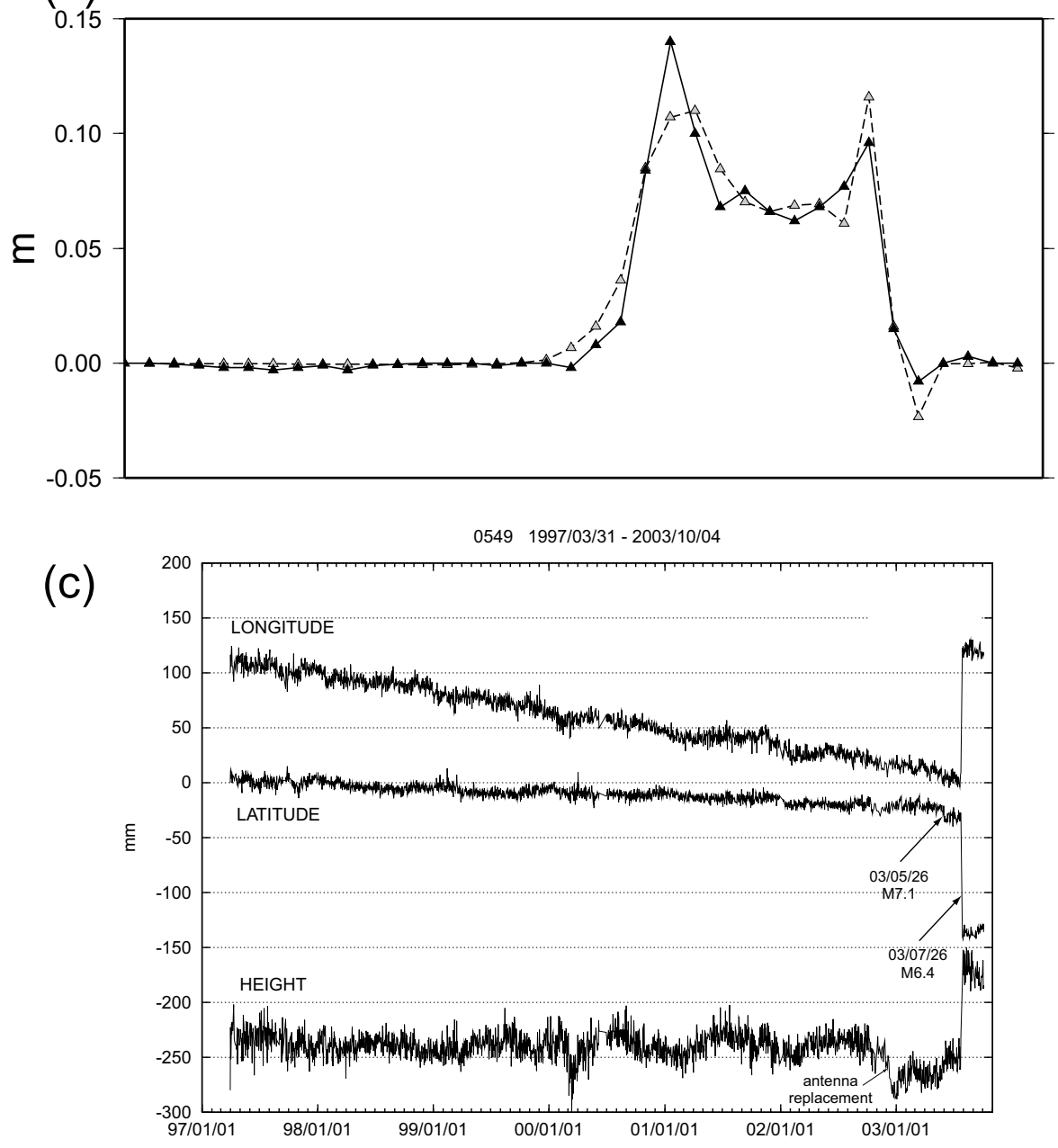

Fig. 2. Coseismic displacements observed by geodetic measurements and calculated from the fault model derived by a geodetic inversion technique (Yabuki and Matsu'ura, 1992). (a) Observed (black) and calculated (gray) horizontal displacements. (b) Observed (black) and calculated (gray) vertical displacements. (c) Time series of site coordinates obtained at Station 0549 of GEONET, which is the closest to the main shock. Remarkable coseismic displacements due to the northern Miyagi earthquake (M6.4) amount to about $16 \mathrm{~cm}$ directed to the southeast, and about $8 \mathrm{~cm}$ of uplift. Minor coseismic displacements at the end of May, 2003, were caused by the May 26 M7.1 earthquake in the subducting slab at a depth of about $70 \mathrm{~km}$ with an epicentral distance of about $60 \mathrm{~km}$ to the northeast of the site. Subsidence in December, 2002, was an artifact of replacing a GPS antenna. 


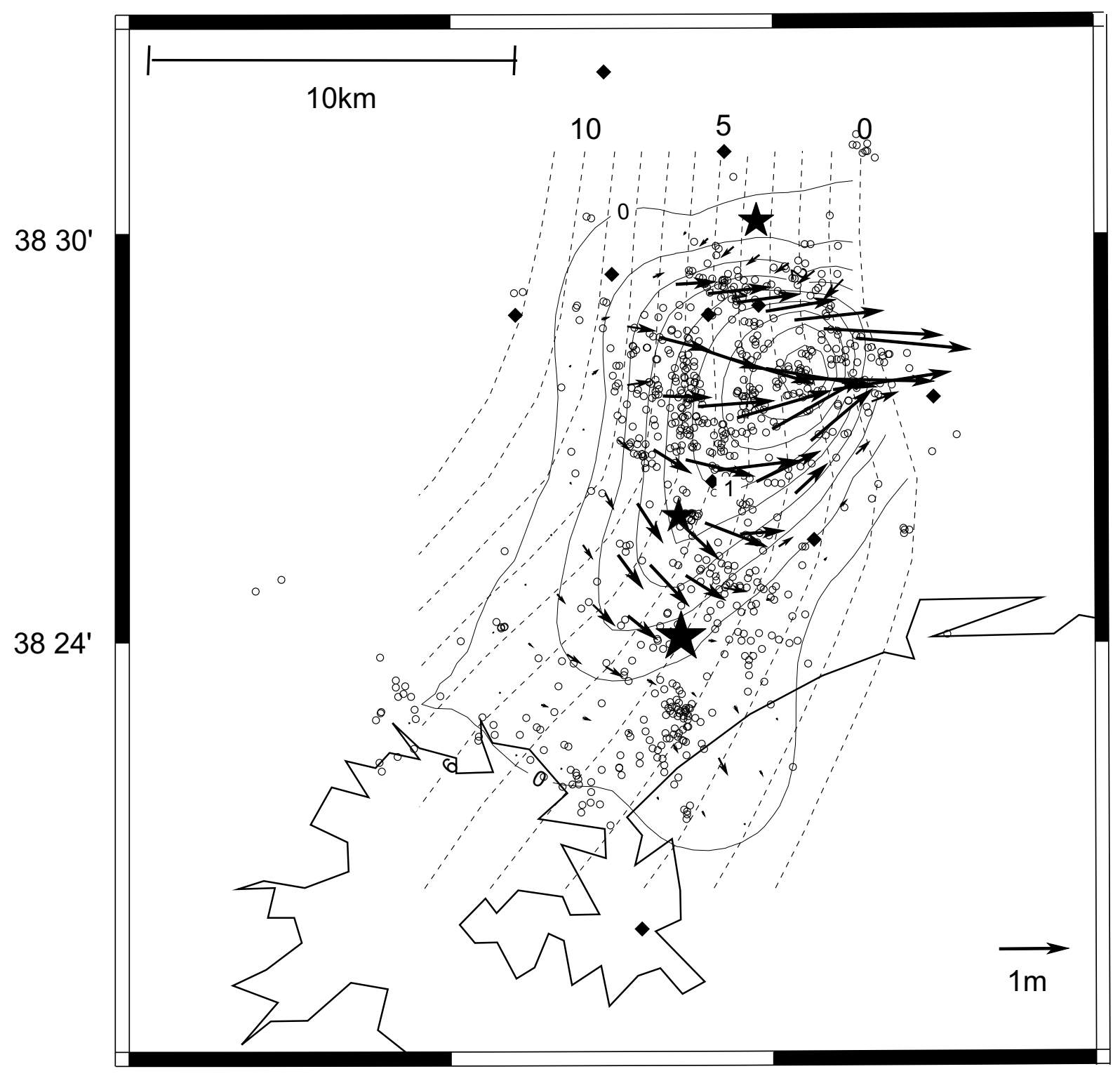

$14100^{\prime}$

$14112^{\prime}$

Fig. 3. Slip distribution estimated by a geodetic inversion technique (Yabuki and Matsu'ura, 1992) as shown by arrows. Broken curves denote the iso-depth contour of the generally westward-dipping model fault with an interval of $1 \mathrm{~km}$. Thin contour lines indicate the amount of slip with an interval of $0.2 \mathrm{~m}$. Small circles are epicenters of aftershocks determined by Okada et al. (2003). Three black stars correspond to the largest aftershock, the largest foreshock, and the main shock, respectively from the north. Black diamonds denote GPS stations.

surface by applying the double-difference hypocenter determination technique (Waldhauser and Ellsworth, 2000) to data from this network together with those from existing permanent seismic stations of Tohoku University, Japan Meteorological Agency, and National Research Institute for Earth Science and Disaster Prevention. We used a geodetic inversion technique devised by Yabuki and Matsu'ura (1992), which can estimate slip distribution even on a curved fault surface. We produced a curved fault surface by fitting a set of bicubic B-spline basis functions to the PHD and assumed 10 by 7 grid points along the strike and dip directions, respectively.

Figure 3 shows the distribution of slip on the curved fault surface estimated by the geodetic inversion. The displacements at the geodetic sites calculated from this slip distribution on the fault surface are shown in Fig. 2. The figure shows that the overall pattern of surface displacement due to the earthquake is reproduced, although there are nonnegligible discrepancies in coseismic displacements at some sites. These may be caused by very local and shallow secondaryfaults, not considered in our model, and/or observational errors such as monument instability. The maximum slip of about $1.6 \mathrm{~m}$ is estimated around the northern and shallower part of the fault plane, where many aftershocks actively occurred at its deeper extension. We summed up the seismic moment at each grid point and derived the total moment of 
(a)

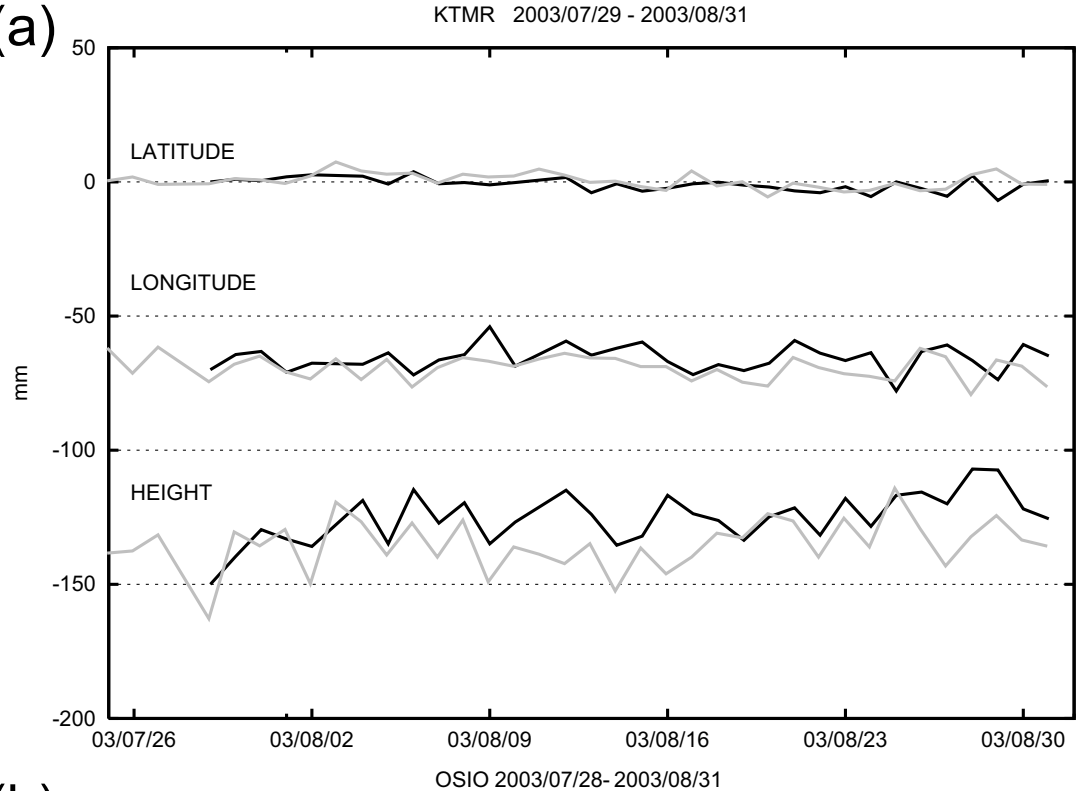

(b)

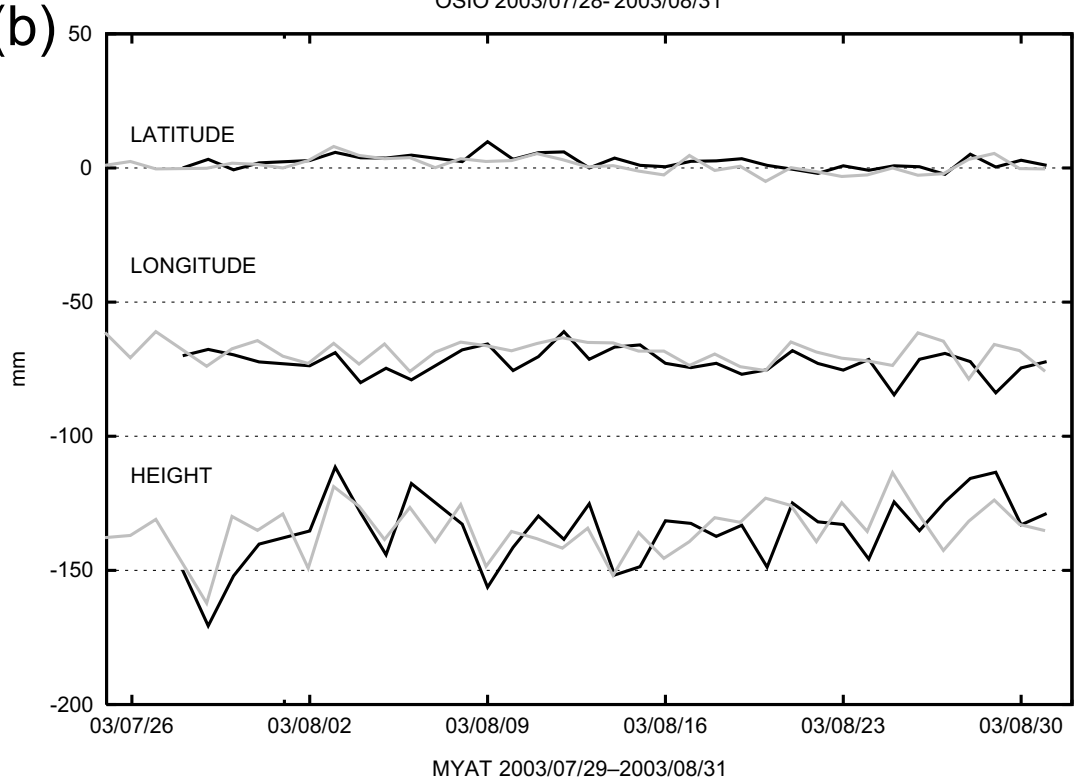

(c)

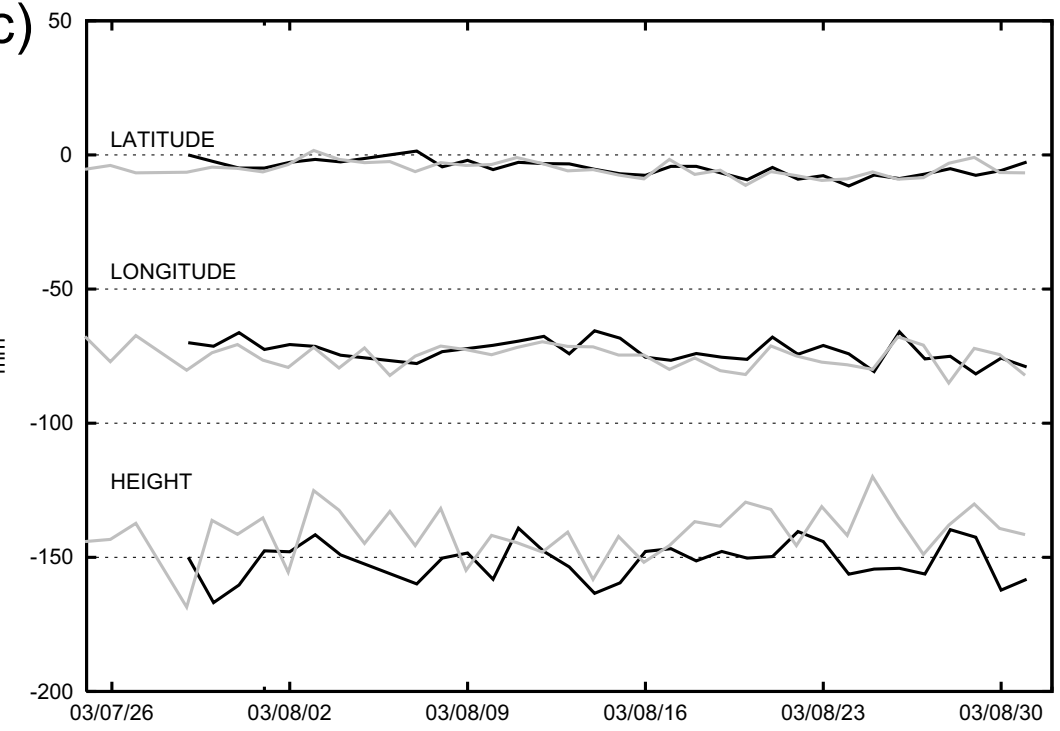

Fig. 4. Time series of coordinates of GPS sites, (a) KTMR, (b) OSIO, and (c) MYAT, for the period from the beginning of observations to the end of August, 2003. Latitudinal, longitudinal, and height components are shown from the top in each panel. Grey lines denote time series at the distant site, WYG, about $30 \mathrm{~km}$ north from the source area, for comparison. GPS data are analyzed using the precise point positioning technique of GIPSY/OASIS-II. 


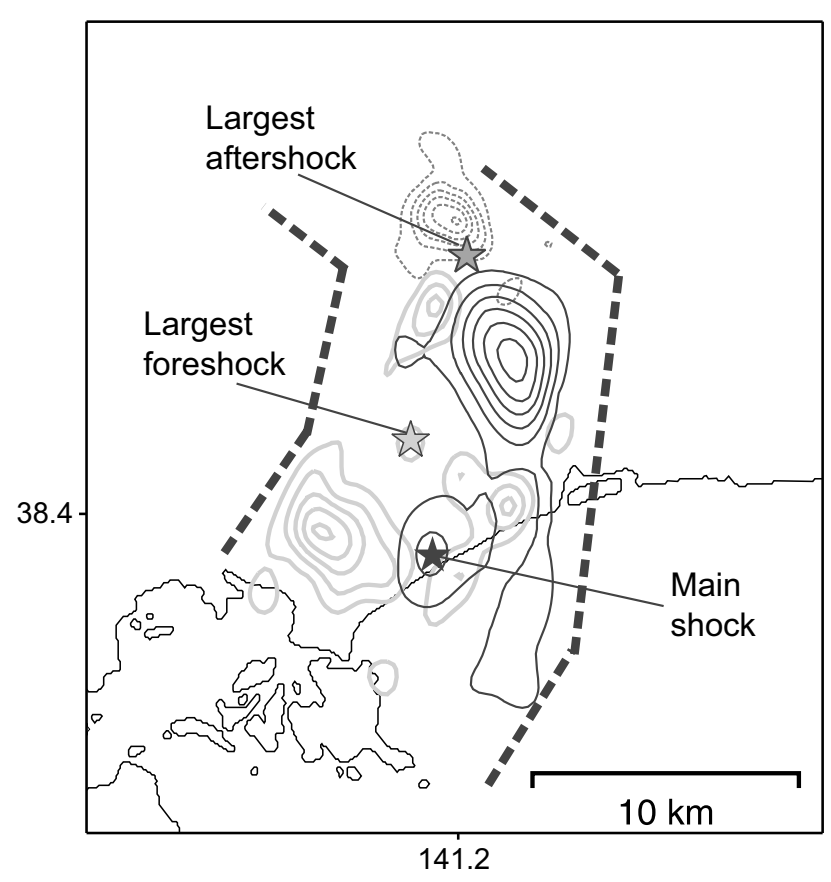

Fig. 5. Slip distributions obtained by seismic waveform inversion (Yagi et al., 2003). Dark gray, light gray, and black stars denote epicenters of the largest aftershock, the largest foreshock, and the main shock, respectively. Gray, black, and broken contour lines are slip distributions for the largest foreshock, the main shock, and the largest aftershock, respectively. Contour interval for the main shock is $0.2 \mathrm{~m}$, and those for the largest foreshock and aftershock are $0.04 \mathrm{~m}$, respectively. Thick broken lines denote shallower (right) and deeper (left) ends of three faults assumed for the waveform inversion of Yagi et al. (2003).

$1.8 \times 10^{18} \mathrm{Nm}\left(M_{w} 6.1\right)$ for the sequence, which is identical to that determined by waveform inversion (Yagi et al., 2003). This means that there was no significant aseisimic slip within a few days before and after the main shock.

\section{Temporary GPS Observations after the Earth- quake}

We initiated temporary GPS observations at three stations just above the source area of the 2003 northern Miyagi earthquake as shown in Fig. 1. We installed an Ashtech GPS receiver with a choke-ring antenna at each site. GPS data are transferred through modems attached to cellular phones at the earlier stage, and then two of those are sent through the Japanese University Satellite Seismic Telemetry Network System (JUSSTN), a satellite communication system (Urabe, 1996) and an ordinary telephone line. GPS data are analyzed using the precise point positioning (PPP) strategy of GIPSY/OASIS-II (Zumberge et al., 1997), which has been used in many geodetic and geophysical applications (e.g. Ohtani et al., 2000; Shoji et al., 2000; Takiguchi et al., 2000). Figure 4 shows time series of site coordinates estimated by the PPP analysis. Comparing with the distant site, WYG, about $30 \mathrm{~km}$ north from the source area, postseismic displacements at all sites are not obvious by the end of $\mathrm{Au}-$ gust 2003.

In the last decade, several articles have been published about postseismic deformation due to inland earthquakes using GPS measurements. Shen et al. (1994) reported postseismic displacements reaching $55 \mathrm{~mm}$ near the epicenter with an exponential time constant of about 34 days after the 1992 Landers earthquake (M7.3). Nakano and Hirahara (1997) detected significant postseismic displacements amounting to $20 \mathrm{~mm}$ with a time constant of about 50 days after the 1995 Hyogo-ken Nanbu earthquake (M7.2). Hashimoto et al. (2003) found postseismic displacements with magnitudes of about $10 \mathrm{~mm}$ around the source area of the 2000 Western Tottori earthquake (M7.3) and estimated parameters of a model fault causing the after-slip.

Ratios of postseismic surface displacements to coseismic ones vary from about $8 \%$ to $15 \%$ for these cases. Simply applying these ratios to the present earthquake, we may expect postseismic displacements between 10 and $20 \mathrm{~mm}$ at the GPS site closest to the source area. Characteristics of postseismic deformation, however, must strongly depend on friction parameters of the main shock fault and/or adjacent faults, together with elastic/inelastic properties around the source area. Thus we should keep a close watch on the course of long-term deformation.

\section{Discussion}

Yagi et al. (2003) carried out seismic waveform inversions and obtained coseismic slip distributions on three fault planes for the largest foreshock, the main shock, and the largest aftershock, respectively. Their result indicates that the maximum slip occurred around the northern part of the aftershock area as shown in Fig. 5. These fault planes are suggested by the aftershock distribution determined by Hinet (High Sensitivity Seismograph Network), maintained by the National Research Institute for Earth Science and Disaster Prevention of Japan (NIED). Because of the difference in fault geometry used, we cannot compare their slip distribution directly with that of this study. However, both results show common characteristics.

Umino et al. (2003) obtained the focal mechanisms and moment tensors of the largest foreshock, the main shock, and the largest aftershock. The results showed that the $P$-axis is oriented E-W for the main shock, NW-SE for the largest foreshock (M5.5), and NE-SW for the largest aftershock (M5.6), respectively. As shown in Fig. 3, the major slips direct mostly eastward in the northern part of the model fault, while slip direction rotates clockwise as one moves south. This is consistent with the spatial variation in the direction of the $P$-axes of focal mechanisms, although the slips directed NE are not estimated in this study.

\section{Conclusion}

We obtained a model of slip distribution on a curved fault plane, reproduced from the results of precise hypocenter determinations, for the 2003 northern Miyagi earthquake sequence. The pattern of the slip distribution shows good agreement with that estimated by waveform inversions and the spatial variation in slip direction is also consistent with the focal mechanisms. No postseismic displacement had been detected by the end of August, 2003, although continuous GPS observations have been conducted at three sites just above the source area from two days after the earthquake. This suggests that inland earthquakes of this size (smaller than M6.5) do not accompany postseismic slip observable with GPS measurements. 
Acknowledgments. The authors are grateful to the Geographical Survey Institute for providing the geodetic data. We also thank two reviewers, Seiichi Shimada and Kosuke Heki for their useful comments and criticisms, and Aaron D. Sweeney for his critical reading of the manuscript.

\section{References}

Hashimoto, M., T. Tabei, T. Sagiya, and T. Ito, A model for the postseismic deformations following the 2000 Western Tottori earthquake (revisited), Prog. and Abstr. Seismol. Soc. Jap. 2003 Fall Meeting, C099, 2003 (in Japanese).

Heki, K., S. Miyazaki, and H. Tsuji, Silent fault slip following an interplate thrust earthquake at the Japan Trench, Nature, 386, 595-597, 1997.

Miura, S., S. Ueki, T. Sato, K. Tachibana, and H. Hamaguchi, Crustal deformation associated with the 1998 seismo-volcanic crisis of Iwate Volcano, Northeastern Japan, as observed by a dense GPS network, Earth Planets Space, 52, 1003-1008, 2000.

Miura, S., T. Sato, K. Tachibana, Y. Satake, and A. Hasegawa, Strain accumulation in and around Ou Backbone Range, northeastern Japan as observed by a dense GPS network, Earth Planets Space, 54, 1071-1076, 2002.

Miyazaki, S., T. Saito, M. Sasaki, Y. Hatanaka, and Y. Iimura, Expansion of GSI's nationwide GPS array, Bull. Geogr. Surv. Inst., 43, 23-34, 1997.

Nakano, T, and K. Hirahara, GPS observations of postseismic deformation for the 1995 Hyogo-ken Nanbu earthquake, Japan, Geophys. Res. Lett., 24, 503-506, 1997.

Nishimura, T., S. Miura, K. Tachibana, K. Hashimoto, T. Sato, S. Hori, E. Murakami, T. Kono, K. Nida, M. Mishina, T. Hirasawa, and S. Miyazaki, Distribution of seismic coupling on the subducting plate boundary in northeastern Japan inferred from GPS observations, Tectonophys., 323, 217-238, 2000.

Nishimura, T., T. Imakiire, H. Yarai, T. Ozawa, M. Murakami, and M. Kaizu, A preliminary fault model of the 2003 July 26, M6.4 northern Miyagi earthquake, northeastern Japan, estimated from joint inversion of GPS, leveling, and InSAR data, Earth Planets Space, 55, 751-757, 2003.

Ohtani, R., N. Koizumi, N. Matsumoto, and E. Tsukuda, Preliminary results from permanent GPS array by the Geological Survey of Japan in conjunction with groundwater-level observations, Earth Planets Space, 52, 663-668, 2000.

Okada T., N. Umino, and A. Hasegawa, Rupture process of July 2003 northern Miyagi earthquake sequence, NE Japan, estimated form doubledifference hypocenter locations, Earth Planets Space, 55, 741-750, 2003.
Sagiya, T., S. Miyazaki, and T. Tada, Continuous GPS array and present-day crustal deformation of Japan, PAGEOPH, 157, 2303-2322, 2000.

Seno, T., K. Shimazaki, P. Somerville, K. Sudo, and T. Eguchi, Rupture process of the Miyagi-Oki, Japan, earthquake of June 12, 1978, Phys. Earth Planet. Inter., 23, 39-61, 1980.

Shen, Z. K., D. D. Jackson, Y. Feng, M. Cline, M. Kim, P. Fang, and Y. Bock, Postseismic deformation following the Landers earthquake, California, 28 June 1992, Bull. Seism. Soc. Am., 84, 780-791, 1994.

Shoji, Y., H. Nakamura, K. Aonashi, A. Ichiki, H. Seko, and Members of GPS/MET Japan Summer Campaign 1997 in Tsukuba, Semi-diurnal and diurnal variation of errors in GPS precipitable water vapor at Tsukuba, Japan caused by site displacement due to ocean tidal loading, Earth Planets Space, 52, 685-690, 2000.

Takiguchi, H., T. Kato, H. Kobayashi, and T. Nakaegawa, GPS observations in Thailand for hydrological applications, Earth Planets Space, 52, 913919, 2000.

Umino, N., T. Okada, J. Nakajima, S. Hori, T. Kono, T. Nakayama, N. Uchida, J. Shimizu, J. Suganomata, G. Shantha, K. Nida, Y. Yabe, K. Sakoda, N. Sato, M. Ito, A. Hasegawa, Y. Asano, A. Hasemi, T. Demachi, and Y. Yajima, Hypocenter and focal mechanism distributions of aftershocks of July 26, 2003, M6.2 northern Miyagi earthquake revealed by temporary observations, J. Seism. Soc. Jap. (Zisin), 2003 (submitted) (in Japanese with English abstract).

Urabe, T., Basic design of an earthquake telemetering system utilizing a communication satellite, Programme Abstr. Seismol. Soc. Jpn., P22, 1996 (in Japanese).

Waldhause, F. and W. L. Ellsworth, A double-difference earthquake location algorithm: method and application to the Northern Hayward fault, Bull. Seism. Soc. Amer., 90, 1353-1368, 2000.

Yabuki, T. and M. Matsu'ura, Geodetic data inversion using a Bayesian information criterion for spatial distribution of fault slip, Geophys. J. Int., 109, 363-375, 1992.

Yagi, Y., Y. Ito, Y. Asano, and S. Sekine, Fore-shock, main-shock, and the largest after-shock associated with the July 262003 Miyagi-ken-hokubu, Japan, earthquake, Prog. and Abstr. Seismol. Soc. Jap. 2003 Fall Meeting, A086, 2003 (in Japanese).

Zumberge, J. F., M. B. Heflin, D. C. Jefferson, M. M. Watkins, and F. H. Webb, Precise point positioning for the efficient and robust analysis of GPS data from large networks, J. Geophys. Res., 102, 5005-5017, 1997.

S. Miura (e-mail: miura@aob.geophys.tohoku.ac.jp), Y. Suwa, T. Sato, K. Tachibana, and A. Hasegawa 